\title{
Self-esteem and Symptoms in Individuals at Clinical High-Risk for Psychosis
}

\author{
Caridad Benavides, MD ${ }^{1}$, Gary Brucato, $\mathrm{PhD}^{2,3}$, and David Kimhy, $\mathrm{PhD}^{1}$ \\ ${ }^{1}$ Department of Psychiatry, Icahn School of Medicine at Mount Sinai, New York, NY \\ ${ }^{2}$ Department of Psychiatry, Columbia University, New York, NY \\ ${ }^{3}$ New York State Psychiatric Institute, New York, NY
}

\begin{abstract}
Individuals with psychotic symptoms often report low global self-esteem (GSE). However, it remains unclear whether the low GSE is linked to the presence of psychotic symptoms or it is present prior to the onset of psychosis. Additionally, the specific subdomains of GSE in these populations are unknown. To address this question, we conducted a cross-sectional study comparing global and SE elements among individuals at clinical high-risk for psychosis (CHR; $n=36$ ), individuals with schizophrenia ( $S C Z ; n=43)$, and healthy controls $(H C ; n=40)$. We then examined among CHR individuals the association between GSE, subdomains, and symptoms. CHR individuals displayed significantly lower GSE compared to $\mathrm{HC}$, at a level comparable to individuals with SCZ. The low GSE was driven primarily by self-perceptions of work and interpersonal relationships abilities. Lower GSE was associated with overall negative and disorganized symptoms severity, but not positive ones. The authors discuss the implications of the findings to interventions development.
\end{abstract}

\section{Keywords}

Clinical High-Risk for Psychosis; Schizophrenia; Self-Esteem; Self-Perception; Self-worth

\section{Introduction}

Self-esteem has long been an area of psychological inquiry, and has recently prompted increased interest in studying its association to psychopathology. Over the past decades, low self-esteem has been linked to the etiology, evolution, and treatment of a wide range of psychiatric conditions (Silverstone, 1991; Roberts and Monroe, 1994; Bardone et al., 2000).

The presence of low self-esteem among individuals with psychotic disorders is well documented (Bowins and Shugar, 1998; Bradshaw and Brekke, 1999; Blairy et al., 2004; Karatzias et al., 2007), and is a contributing factor in the formation of psychotic symptoms

Corresponding author: Dr. Caridad Benavides, Department of Psychiatry, PRISM (Psychosis Research Integrating Science and Medicine), Icahn School of Medicine at Mount Sinai, 53-55 E 96th St 1st Fl, Room 1A13, New York, NY 10029, Phone: (212) 659-8749, drbenavidesc@gmail.com.

Conflicts of Interest statement: None of the authors had any conflict of interest relating to this project. 
(Bentall et al., 1994; Garety et al., 2001; Smith et al., 2006; Warman et al., 2010). Negative self-evaluation in schizophrenia (SCZ) is linked to the severity and maintenance of delusions and hallucinations (Kesting et al., 2013), higher suicidal risk (Siris, 2001; Kontaxakis et al., 2004; Tarrier et al., 2004), more relapses (Holding et al., 2013), and poor subjective quality of life (Hansson et al., 1999; Kunikata et al., 2005; Ritsner et al., 2003). Research shows that patients with SCZ do not uniformly have lower global self-esteem (GSE) compared with healthy controls (HC), but rather, have specific domains of self-esteem affected, like value of work or social relationships (Garfield et al., 1987; Dongen et al., 1998). Among individuals at clinical high risk (CHR) for psychosis, results suggest they possess more negative selfbeliefs than HC (Perivoliotis et al., 2009; Stowkowy and Addington, 2012) and such views have been associated with higher distress at the onset of the illness (Vracotas et al., 2012).

Conceptualizations of self-esteem have ranged from viewing it as a unidimensional global index (Coopersmith, 1967; Robins et al., 2002; Rosenberg, 1965) to one with multiple domains (Harter, 1986; Heatherton and Baumeister, 1991). The assessments of self-esteem also ranged from the explicit concept to an implicit one. The most accepted in research is the explicit concept of self-esteem, which requires respondents to self-report on their conscious feelings about the self. This concept contrasts with the implicit one, which attempts to use the non-conscious concept of self, i.e. Implicit Association Tests (IAT; Greenwald et al., 1998).

Traditionally, self-esteem in SCZ was measured using a global score (Rosenberg et al., 1995), mainly due to time constrictions in longitudinal studies. However, self-esteem in psychosis has recently been described as having a paradoxical quality. The prevailing models reveal that a multidimensional focus, in which domain-specific self-concepts are assessed, far more adequately describes the phenomenology of self-description and selfevaluation (Magaud et al., 2013).

Harter and colleagues proposed a distinctive multidimensional model that highlights the interaction between the individual's judgments of their competence within a domain (i.e., being athletic), and the value they assign to it. Using this model, individuals who perceive success in athletic tasks and who also deem athleticism as important will have an increased self-esteem. Likewise, those who don't perceive success in a given task and who also don't deem it as important would not have their self-esteem affected. Harter scales, including the Self-Perception Profile for Adults (SPPA; Harter, 1986; Messer and Harter, 2012), are widely used in literature to measure self-esteem in individuals with mental and physical health disorders, especially within adolescent populations (Donnellan, 2005; Jerome, 2002; Van Damme et al., 2014).

Harter's scale offers many advantages, including providing the ability to obtain both a global and a range of domain specific self-esteem ratings. It also provides the unique ability to evaluate the importance (importance of a domain to the individuals) and discrepancy scores (difference between one's competency judgments, and the importance the individual attaches to success in each domain). Previous reports have linked high discrepancy scores with the onset of several mental health disorders (Kinderman et al., 1996; Vater et al., 2010; Creemers et al., 2012). 
While self-esteem has been studied extensively in individuals with SCZ, little is known about self-esteem in CHR individuals. Specifically, the effects of different domains of selfesteem and their importance and discrepancy scores in the population at risk for psychosis remain unknown. Thus, our aims were to: 1) characterize self-esteem, discrepancy, and importance scores among individuals at CHR and compare them to individuals with SCZ and $\mathrm{HC}$; and 2) to assess the association of self-esteem, discrepancy, and importance scores with the range of symptoms among CHR individuals. We hypothesized that CHR participants would score intermediate to the other two groups, with individuals with SCZ displaying the lowest self-esteem scores and the highest discrepancy and importance scores. We further hypothesized that, among CHR participants, lower self-esteem scores, and higher discrepancy and importance scores would be correlated with greater symptom severity.

\section{Methods}

\subsection{Participants}

We conducted a cross-sectional comparison of GSE, discrepancy, and importance scores among help-seeking individuals at CHR for psychosis, individuals with SCZ, and HC. The CHR group was recruited from the Center of Prevention and Evaluation in Psychosis, a New York State Psychiatric Institute (NYSPI) CHR research program housed at Columbia University Medical Center. Data on individuals with SCZ and HC were obtained from two longitudinal studies conducted at NYSPI. All participants provided written consent and the studies were approved by the NYSPI Institutional Review Board.

The sample included 119 participants; 36 CHR individuals, 43 with SCZ, and 40 HC. All CHR participants met criteria for Attenuated Positive Symptom Syndrome (APSS), defined with the Structured Interview for Prodromal Symptoms, (SIPS; Miller et al. 2003). This criterion requires 1 ) that one or more Positive symptom is scored between 3 and 5 , is new or has worsened by $\geq 1$ point in the past year, and 2) that no score of 6 on a Positive symptom has ever been achieved, (since a score of 6 on SIPS positive symptoms is indicative of threshold psychosis). Additionally, all CHR met criteria for the Attenuated Psychosis Syndrome (APS) proposed in the appendix of the fifth edition of the Diagnostic and Statistical Manual of Mental Disorders, (DSM; American Psychiatric Association, APA, 2013), which differ from APSS criteria only in that the latter also requires symptoms to be sufficiently distressing and disabling to prompt help-seeking.

\subsection{Inclusion/Exclusion criteria}

For the CHR individuals, the inclusion criteria were a CHR status as determined by the SIPS (Miller et al., 2003); age 14-30 years; English-speaking; and capacity to provide informed consent. The exclusion criteria included major medical or neurological problems better accounting for symptoms; intelligence quotient (IQ) $<70$; significant risk of harm to self and/or others; and/or 'prodromal' symptoms temporarily related to substance or alcohol use. For the SCZ group, the inclusion criteria were age 18-50 years; English-speaking; a DSMIV (APA, 2000) diagnosis of SCZ, schizoaffective disorder or schizophreniform disorder; and capacity to provide informed consent. The exclusion criteria were use of street drugs within the past 4 weeks (confirmed via urine toxicology test), history of neurological 
disorder or loss of consciousness; IQ < 70; and a recent history of serious suicidal/aggressive behavior. For the HC participants, the inclusion criteria were age 18-50 years and Englishspeaking. The exclusion criteria were a history of psychotic symptoms; a diagnosis of any DSM-IV Axis I, Axis II cluster A personality disorder; IQ < 70; a first-degree family member with history of psychosis and having been adopted.

\subsection{Measures}

DSM-IV diagnoses were determined for all participants with the semi-structured Diagnostic Interview for Genetic Studies (Nurnberger et al., 1994). In the SCZ group, psychotic symptoms were assessed using the Scales for Assessment of Positive and Negative Symptoms (SAPS/SANS; Andreasen, 1982). A single psychiatrist participated in all of these diagnostic assessments and, immediately following, rated each subject using the PANSS.

CHR Status and Prodromal Symptoms were assessed using the SIPS, which contains the 19symptom Scale of Prodromal Symptoms (SOPS; Hawkins et al., 2004). This semi-structured diagnostic interview identifies individuals at CHR for psychosis based upon the presence of either attenuated psychotic symptoms, brief intermittent psychotic symptoms, or genetic risk (first-degree family member with past or current psychosis and/or Schizotypal Personality Disorder), accompanied by a 30\% or more decline in Global Assessment of Functioning score (GAF; Hall, 1995) relative to the highest GAF in the past year. A Master's degree researcher administered the SIPS/SOPS.

Self-esteem was measured with the Harter's SPPA scale, a 50-item self-report questionnaire examining GSE. The SPPA includes eleven sub-domains of self-esteem: Sociability, Job Competence, Nurturance, Athletics, Physical Appearance, Adequacy as Provider, Morality, Household Management, Intimate Relationships, Intelligence and Sense of Humor. Harter's SPPA scale has largely been shown to have satisfactory psychometric properties including reliability and validity (Elfhag et al., 2010). Items of the SPPA contain two contrasting statements. One statement is on the left side of the page, and the other is on the right, with the two statements separated by the capitalized word "BUT" (e.g., "some people question if they are worthwhile BUT other people feel that they are a worthwhile person"). Participants were first asked to choose the statement that describes them more accurately, and then decide whether the statement is "really true" or "sort of true" to them. The score for each item can range from one (not true at all) to four (really true'). This format was designed to reduce tendencies to give socially desirable responses. Subdomain scores of GSE in the SPPA are derived by averaging the item scores within its respective subdomain. Importance ratings are assessed by asking the participants to rate the importance they give to each of the eleven subdomains in their lives, using a Likert scale from one (not very important) to four (very important). Only domains scored as very important are included. Finally, to obtain the overall discrepancy score, the average GSE score is subtracted from the importance rating for only those domains rated as very important. For example, if a participant considered the Athletics subdomain very important (score of 4), and obtained an average GSE score of 1 in this subdomain, the discrepancy score for the subscale Athletics would be 3 for this participant (Discrepancy score $=$ Importance score - GSE score). 


\subsection{Procedures}

After satisfying the inclusion/exclusion criteria, all participants completed the diagnostic and clinical interviews, along with the self-esteem assessments, typically within one to two weeks of admission to their respective studies. Additionally, the CHR participants were interviewed as part of a longitudinal study to assess conversion to psychosis using the SIPS/ SOPS.

\subsection{Statistical Analyses}

Analyses were carried out using IBM SPSS version 22 . The sample was normally distributed as confirmed by the Levene test for GSE, importance, and discrepancy scores. For all scores, an ANOVA model was carried out, followed by posthoc comparisons between the groups, which were adjusted for multiple hypotheses using a Bonferroni correction. Instead of adjusting the alpha, for ease of interpretation, SPSS uses a Bonferroni adjusted P value. This is calculated in SPSS by multiplying the actual $p$ value by the number of comparisons adjusted for (i.e., 3). Among the CHR individuals, associations between GSE, discrepancy scores, and symptoms were examined using Pearson correlations. For the exploratory analyses, we also conducted an ANOVA model followed by posthoc comparisons adjusted for multiple hypotheses using Bonferroni correction.

\section{Results}

The sample's demographic and clinical data are presented in Table 1. There were no significant group differences in sex, race, ethnicity, or religious affiliation. However, the SCZ group was significantly older than the CHR and HC groups. The GSE, importance, and discrepancy scores were not significantly associated with age, sex, race, or ethnicity.

Our first aim was to characterize GSE, discrepancy, and importance scores across the three groups. We conducted three one-way ANOVA, with GSE, discrepancy, and importance scores entered separately as the dependent variables, and clinical status (CHR, SCZ, HC) entered as the independent variables. The first ANOVA indicated significant group differences in the GSE scores (F2,116=16.92, p<0.001), with the CHR and SCZ groups having significantly lower GSE (See Table 2; $\mathrm{M}=14.55, \mathrm{SD}=4.34$ and $\mathrm{M}=14.72, \mathrm{SD}=5.42$, respectively) compared to the $\mathrm{HC}$ group ( $\mathrm{M}=19.90, \mathrm{SD}=3.99$; See Figure 1). Exploratory analyses among the $36 \mathrm{CHR}$ individuals indicated GSE was most closely associated with self-perception in the sub-domains of provider $(r=.53, p<.001)$, physical appearance $(r=.37$, $\mathrm{p}=.026)$, sense of humor $(\mathrm{r}=.45, \mathrm{p}=.006)$, intimate relations $(\mathrm{r}=.45, \mathrm{p}=.006)$, and job competence $(\mathrm{r}=.39, \mathrm{p}=.018)$. A second ANOVA indicated significant group differences in discrepancy scores $(\mathrm{F} 2,116=3.96, \mathrm{p}<.05)$. The $\mathrm{SCZ}$ group received significantly higher discrepancy scores $(\mathrm{M}=6.52, \mathrm{SD}=4.71)$ compared to $\mathrm{HC}(\mathrm{M}=4.08, \mathrm{SD}=3.42)$, and the $\mathrm{CHR}$ group intermediate scores $(\mathrm{M}=5.51, \mathrm{SD}=3.50)$. Finally, there were no significant differences in importance scores $(\mathrm{F} 2,116=2.24, \mathrm{p}=.11)$ between the groups compared.

Our second aim was to examine the associations between GSE, discrepancy, and importance scores and prodromal symptoms among the CHR individuals. The results are presented in Table 3. GSE was not significantly correlated with overall positive symptom severity, or with 
any specific SIPS positive symptoms. However, GSE was significantly inversely associated with overall negative symptom severity. Exploratory analyses indicated that this association was driven primarily by significant correlations with the SIPS negative symptoms items of social isolation and withdrawal $(\mathrm{N} 1 ; \mathrm{r}=-.49, \mathrm{p}=0.003)$ and decreased experience of emotions $(\mathrm{N} 4 ; \mathrm{r}=-.39, \mathrm{p}=0.021)$. GSE was also significantly inversely correlated with overall disorganization, driven primarily by a correlation with the SIPS item assessing odd behavior and appearance (D1; r=-.47, p=0.004). Finally, GSE was also significantly inversely correlated with overall general symptoms (GS; $r=-.42, p=0.014)$.

In the SCZ group, we found statistically significant correlations between low GSE scores and Positive and Negative Symptoms, as measured by the SAPS and SANS total. We found a negative correlation between GSE score and SANS total $(\mathrm{r}=-.54, \mathrm{n}=56, \mathrm{p}<0.001)$, as well as SAPS $(\mathrm{r}=-.32, \mathrm{n}=56, \mathrm{p}=0.001)$.

Importance scores -the number of domains marked as Very Important (i.e., score=4)- were not significantly correlated with SIPS overall positive symptom severity, or with any specific SIPS positive symptoms. However, importance scores were inversely correlated with overall severity of negative and disorganized symptoms, driven primarily by significant correlations with the specific SIPS items of avolition ( $\mathrm{N} 2 ; \mathrm{r}=-.55, \mathrm{p}=0.001)$, deterioration in role functioning (N6; r=-.42, p=0.013), and personal hygiene ( $\mathrm{D} 4 ; \mathrm{r}=-.49, \mathrm{p}=0.003$ ). Discrepancy scores were not significantly correlated with any SIPS overall symptom domain severity.

\section{Discussion}

To the best of our knowledge, the present study is the first comprehensive investigation in self-esteem sub-domains and discrepancies, and their link to symptoms in CHR individuals. One of the key findings is that CHR individuals display significantly lower self-esteem compared to $\mathrm{HC}$, at a level comparable to individuals with $\mathrm{SCZ}$, consistent with previous reports (Pruessner et al., 2011). Low GSE in the CHR group was driven primarily by each individual's view of their abilities related to work and interpersonal relationships, specifically, those related to job competence and being able to provide for others. Additionally, physical appearance, sense of humor, and intimate relationships were closely associated with GSE scores in this population.

Examination of the links between self-esteem and symptoms in the CHR individuals indicated associations with overall ratings of disorganized and, in particular, negative symptoms. These associations were driven primarily by social functioning-related symptoms including social isolation and withdrawal, odd behavior and appearance, and decreased experience of emotions. These findings were consistent with cognitive models of negative symptoms in SCZ that suggest links between negative symptoms and low estimation of one's ability to succeed and/or enjoy future activities (Grant and Beck, 2009, 2010; Rector et al., 2005). The connection of low GSE to decreased affective experience in CHR individuals before conversion to full psychosis was consistent with previous reports of significant relationships between poor emotional awareness (i.e., alexithymia) and poor social functioning in CHR individuals (Kimhy et al., 2016) and individuals with SCZ (Kimhy et al., 2012). 
In contrast, the lack of association between GSE and positive symptoms may be due to such symptoms involving both diminished (i.e., guilt, paranoia) and elevated (i.e., grandiosity) perceptions of the self. This lack of significant correlation with positive symptoms differs from the results published on subjects with established SCZ (Freeman et al., 1998; Bentall et al., 2008), which may be an aspect worthwhile of future research, as it is a possible characteristic that distinguishes subjects at CHR from those with full-blown psychosis. In a recent study (Bird et al., 2017), a possible link between the maintenance of paranoia and low self-esteem was observed in a young population. However, the characteristics of this population also differed from the present study since they were chosen based on suspected paranoid ideation, irrespective of psychiatric diagnosis. According to social comparison theories of self-esteem, individuals determine their own worth based on comparisons to others (Suls et al., 1991). Therefore, our findings in positive symptoms could also be the result of CHR individuals comparing themselves to their non-clinical peers, while people with SCZ are more likely to judge themselves based on their comparison to other individuals with chronic illnesses. Also, other factors like ethnicity seem to account for differences in the relationship between positive symptoms and reduced self-esteem (Ciufolini et al., 2015).

Our findings may have clinical and research implications. Given that GSE in CHR individuals was driven primarily by self-perceptions related to job and social abilities, interventions aiming to address low GSE in this population may need to address these domains, especially when targeting negative symptoms. Potentially related to this, recent studies demonstrated that treatment targeting self-esteem resulted in clear clinical benefits, including decreased psychotic symptomatology and improved social functioning, and such results were maintained at a 3-month follow-up (Hall et al., 2003). Future research focusing on the targeting of low GSE and its different dimensions among CHR individuals should be performed to explore its long-term potential impact on the spectrum of psychosis. The focus of our investigation was on adult-relevant domains of self-perception, including job competence and status as a provider. These findings may not apply as well to younger CHR individuals in which a focus on work-related issues would not be as prominent, although they can be applied to individuals' sense of productivity at any age.

The present study has a number of potential limitations. First, given the relatively small sample, our results should be considered preliminary until replicated in larger samples. In addition, the cross-sectional nature of this study requires caution when analyzing results. Likewise, reliability information has not been reported. Intraclass correlation coefficient could not be calculated because the item data was not available. Finally, assessment of GSE in the present study was based on self-report questionnaires. Evidence from SCZ studies suggests that interview-based methods of assessing self-esteem may be superior to assessments via questionnaires (Barrowclough et al., 2003).

In summary, this investigation demonstrates that low self-esteem, which is prevalent in SCZ, is also present to a comparable degree of severity in CHR individuals. Our findings help to better understand the CHR period and may suggest targets for early psychosocial treatments aimed at improving social and occupational functioning, as such domains appear to play an important role in determining GSE in this population. The examination of different dimensions of self-esteem in the assessment of CHR populations may contribute to a better 
understanding of the phenomenology of prodromal symptoms, and thus, may have implications for finding successful early therapeutic approaches, rehabilitation, and social integration for a condition that is accompanied by considerable suffering and risk of suicide.

\section{Acknowledgments}

The authors thank Daliah H Ross for her valuable assistance in the technical editing and proofreading process. We also thank Dr. Girgis and Dr. Chan for their expert assistance in preparing the manuscript.

Sources of funding: This study was supported by NIMH Grant 1K23MH077653 (to Dr. Kimhy). The first author (Dr. Benavides) was supported by the Alicia Koplowitz Foundation for the completion of her Fellowship in Child and Adolescent Psychiatry and PhD Dissertation under the supervision of Dr. Arango.

\section{References}

American Psychiatric Association. Diagnostic and statistical manual of mental disorders: DSM-5. Washington, D.C: American Psychiatric Association; 2013.

Andreasen NC. Negative Symptoms in Schizophrenia: definition and reliability. Arch Gen Psychiat. 1982; 39:784-8. 1982. [PubMed: 7165477]

Bardone AM, Vohs KD, Abramson LY, Heatherton TF, Joiner TE. The confluence of perfectionism, body dissatisfaction, and low self-esteem predicts bulimic symptoms: Clinical implications. Behavior Therapy. 2000; 31(2):265-280.

Barrowclough C, Tarrier N, Humphreys L, Ward J, Gregg L, Andrews B. Self-esteem in schizophrenia: relationships between self-evaluation, family attitudes, and symptomatology. J Abnorm Psychol. 2003; 112(1):92-99. [PubMed: 12653417]

Beck AT, Brown G, Steer RA, Eidelson JI, Riskind JH. Differentiating anxiety and depression: a test of the cognitive content-specificity hypothesis. J Abnorm Psychol. 1987; 96(3):179-183. [PubMed: 3680754]

Bentall RP, Kinderman P, Kaney S. The self, attributional processes and abnormal beliefs: towards a model of persecutory delusions. Behav Res Ther. 1994; 32(3):331-341. [PubMed: 8192633]

Bentall RP, Rouse G, Kinderman P, Blackwood N, Howard R, Moore R, Cummins S, Corcoran R. Paranoid delusions in schizophrenia spectrum disorders and depression: the transdiagnostic role of expectations of negative events and negative self-esteem. The Journal of nervous and mental disease. 2008; 196(5):375-383. [PubMed: 18477879]

Bird JC, Waite F, Rowsell E, Fergusson EC, Freeman D. Cognitive, affective, and social factors maintaining paranoia in adolescents with mental health problems: A longitudinal study. Psychiatry Res. 2017; 257(7):34-39. [PubMed: 28715666]

Blairy S, Linotte S, Souery D, Papadimitriou GN, Dikeos D, Lerer B, Kaneva R, Milanova V, Serretti A, Macciardi F, Mendlewicz J. Social adjustment and self-esteem of bipolar patients: a multicentric study. J Affect Disord. 2004; 79(1-3):97-103. [PubMed: 15023484]

Bowins B, Shugar G. Delusions and self-esteem. Can J Psychiatry. 1998; 43(2):154-158. [PubMed: 9533968]

Bradshaw W, Brekke JS. Subjective experience in schizophrenia: factors influencing self-esteem, satisfaction with life, and subjective distress. Am J Orthopsychiatry. 1999; 69(2):254-260. [PubMed: 10234391]

Ciufolini S, Morgan C, Morgan K, Fearon P, Boydell J, Hutchinson G, Demjaha A, Girardi P, Doody GA, Jones PB, Murray R, Dazzan P. Self-esteem and self agency in first episode psychosis: Ethnic variation and relationship with clinical presentation. Psychiatry Res. 2015 Jun 30; 227(2-3):213-8 [PubMed: 25868868]

Coopersmith S. The antecedents of self-esteem. Consulting Psychologists Pr. 1967

Creemers DH, Scholte RH, Engels RC, Prinstein MJ, Wiers RW. Implicit and explicit self-esteem as concurrent predictors of suicidal ideation, depressive symptoms, and loneliness. J Behav Ther Exp Psychiatry. 2012; 43(1):638-646. [PubMed: 21946041] 
Dongen CJV. Self-esteem among persons with severe mental illness. Issues in mental health nursing. 1998; 19(1):29-40. [PubMed: 9479100]

Donnellan M. Low Self-Esteem Is Related to Aggression, Antisocial Behavior, and Delinquency. Psychological Science. 2005

Elfhag K, Tynelius P, Rasmussen F. Self-esteem links in families with 12-year-old children and in separated spouses. J Psychol. 2010; 144(4):341-359. [PubMed: 20617762]

Freeman D, Garety P, Fowler D, Kuipers E, Dunn G, Bebbington P, Hadley C. The London-East Anglia randomized controlled trial of cognitive-behaviour therapy for psychosis IV: Self-esteem and persecutory delusions. British Journal of Clinical Psychology. 1998; 37(4):415-430. [PubMed: 9856295]

Garety PA, Kuipers E, Fowler D, Freeman D, Bebbington PE. A cognitive model of the positive symptoms of psychosis. Psychological medicine. 2001; 31(2):189-195. [PubMed: 11232907]

Garfield DA, Rogoff ML, Steinberg S. Affect recognition and self-esteem in schizophrenia. Psychopathology. 1987; 20(5-6):225-233. [PubMed: 3454445]

Grant PM, Beck AT. Defeatist beliefs as a mediator of cognitive impairment, negative symptoms, and functioning in schizophrenia. Schizophr Bull. 2009; 35(4):798-806. [PubMed: 18308717]

Grant PM, Beck AT. Asocial beliefs as predictors of asocial behavior in schizophrenia. Psychiatry Res. 2010; 177(1-2):65-70. [PubMed: 20163875]

Greenwald AG, McGhee DE, Schwartz JL. Measuring individual differences in implicit cognition: the implicit association test. J Pers Soc Psychol. 1998; 74(6):1464-1480. [PubMed: 9654756]

Hall RC. Global assessment of functioning. A modified scale. Psychosomatics. 1995; 36(3):267-275. [PubMed: 7638314]

Hall PL, Tarrier N. The cognitive-behavioural treatment of low self-esteem in psychotic patients: a pilot study. Behaviour research and therapy. 2003; 41(3):317-332. [PubMed: 12600402]

Hansson L, Middelboe T, Merinder L, Bjarnason O, Bengtsson-Tops A, Nilsson L, Sandlund M, Sourander A, Sørgaard KW, Vinding H. Predictors of subjective quality of life in schizophrenic patients living in the community. A Nordic multicentre study. International Journal of Social Psychiatry. 1999; 45(4):247-258. [PubMed: 10689608]

Harter SM, M B. The self-perception profile for adults; manula and questionnaires. 1986

Hawkins KA, McGlashan TH, Quinlan D, Miller TJ, Perkins DO, Zipursky RB, Addington J, Woods SW. Factorial structure of the Scale of Prodromal Symptoms. Schizophrenia research. 2004; 68(2): 339-347. [PubMed: 15099615]

Heatherton TF, Baumeister RF. Binge eating as escape from self-awareness. Psychol Bull. 1991; 110(1):86-108. [PubMed: 1891520]

Holding JC, Tarrier N, Gregg L, Barrowclough C. Self-esteem and relapse in schizophrenia: a 5-year follow-up study. J Nerv Ment Dis. 2013; 201(8):653-658. [PubMed: 23896845]

James W. Principles of psychology. 1890; 1

Jerome A. Self-Esteem in Children With Specific Language Impairment. Journal of Speech, Language, and Hearing Research. 2002

Karatzias T, Gumley A, Power K, O'Grady M. Illness appraisals and self-esteem as correlates of anxiety and affective comorbid disorders in schizophrenia. Compr Psychiatry. 2007; 48(4):371375. [PubMed: 17560959]

Kesting ML, Bredenpohl M, Klenke J, Westermann S, Lincoln TM. The impact of social stress on selfesteem and paranoid ideation. Journal of behavior therapy and experimental psychiatry. 2013; 44(1):122-128. [PubMed: 22960709]

Kimhy D, Vakhrusheva J, Jobson-Ahmed L, Tarrier N, Malaspina D, Gross JJ. Emotion awareness and regulation in individuals with schizophrenia: Implications for social functioning. Psychiatry Res. 2012; 200(2-3):193-201. [PubMed: 22749227]

Kimhy D, Gill KE, Brucato G, Vakhrusheva J, Arndt L, Gross JJ, Girgis RR. The impact of emotion awareness and regulation on social functioning in individuals at clinical high risk for psychosis. Psychological medicine. 2016; 46(14):2907-2918. [PubMed: 27050714]

Kinderman P, Bentall RP. Self-discrepancies and persecutory delusions: evidence for a model of paranoid ideation. J Abnorm Psychol. 1996; 105(1):106-113. [PubMed: 8666699] 
Kontaxakis V, Havaki-Kontaxaki B, Margariti M, Stamouli S, Kollias C, Christodoulou G. Suicidal ideation in inpatients with acute schizophrenia. The Canadian Journal of Psychiatry. 2004; 49(7): 476-479. [PubMed: 15362252]

Kunikata H, Mino Y, Nakajima K. Quality of life of schizophrenic patients living in the community: The relationships with personal characteristics, objective indicators and self-esteem. Psychiatry and Clinical neurosciences. 2005; 59(2):163-169. [PubMed: 15823162]

Magaud E, Marshall C, Mancuso E, Addington J. Use of the Self-Esteem Rating Scale-Short Form in a first episode of psychosis sample. Schizophrenia research. 2013; 143(2):399-400. [PubMed: 23265776]

Messer B, Harter S. The Self-Perception Profile for Adults : Manual and Questionnaires. 2012

Miller TJ, McGlashan TH, Rosen JL, Cadenhead K, Cannon T, Ventura J, McFarlane W, Perkins DO, Pearlson GD, Woods SW. Prodromal assessment with the structured interview for prodromal syndromes and the scale of prodromal symptoms: predictive validity, interrater reliability, and training to reliability. Schizophr Bull. 2003; 29(4):703-715. [PubMed: 14989408]

Nurnberger JI, Blehar MC, Kaufmann CA, York-Cooler C, Simpson SG, Harkavy-Friedman J, Severe JB, Malaspina D, Reich T. Diagnostic interview for genetic studies. Rationale, unique features, and training. NIMH Genetics Initiative. 1994:849-859. discussion 863-864.

Perivoliotis D, Morrison AP, Grant PM, French P, Beck AT. Negative performance beliefs and negative symptoms in individuals at ultra-high risk of psychosis: a preliminary study. Psychopathology. 2009; 42(6):375-379. [PubMed: 19752591]

Pruessner M, Iyer SN, Faridi K, Joober R, Malla AK. Stress and protective factors in individuals at ultra-high risk for psychosis, first episode psychosis and healthy controls. Schizophrenia research. 2011; 129(1):29-35. [PubMed: 21497058]

Rector NA, Beck AT, Stolar N. The negative symptoms of schizophrenia: a cognitive perspective. Can J Psychiatry. 2005; 50(5):247-257. [PubMed: 15968839]

Ritsner M, Kurs R, Gibel A, Hirschmann S, Shinkarenko E, Ratner Y. Predictors of quality of life in major psychoses: a naturalistic follow-up study. Journal of Clinical Psychiatry. 2003; 64(3):308315. [PubMed: 12716273]

Roberts JE, Monroe SM. A Multidimensional Model of Self-Esteem in Depression. Clinical Psychology Review. 1994; 14(3):161-181.

Robins RW, Trzesniewski KH, Tracy JL, Gosling SD, Potter J. Global self-esteem across the life span. Psychol Aging. 2002; 17(3):423-434. [PubMed: 12243384]

Robson PJ. Self-esteem - A psychiatric view. 1988:6-15.

Rosenberg, M. Society and the adolescent self-image. Vol. 11. Princeton, NJ: Princeton university press; 1965. p. 326

Rosenberg M, Schooler C, Schoenbach C, Rosenberg F. Global self-esteem and specific self-esteem: Different concepts, different outcomes. American sociological review. 1995:141-156.

Silverstone PH. Low self-esteem in different psychiatric conditions. Br J Clin Psychol. 1991; 30(Pt 2): 185-188. [PubMed: 2059753]

Siris SG. Suicide and schizophrenia. Journal of psychopharmacology. 2001; 15(2):127-135. [PubMed: 11448086]

Smith B, Fowler DG, Freeman D, Bebbington P, Bashforth H, Garety P, Dunn G, Kuipers E. Emotion and psychosis: Links between depression, self-esteem, negative schematic beliefs and delusions and hallucinations. Schizophrenia Research. 2006; 86(1-3):181-188. [PubMed: 16857346]

Stowkowy J, Addington J. Maladaptive schemas as a mediator between social defeat and positive symptoms in young people at clinical high risk for psychosis. Early Interv Psychiatry. 2012; 6(1): 87-90. [PubMed: 21951894]

Suls, JE., Wills, TAE. Social comparison: Contemporary theory and research. Lawrence Erlbaum Associates, Inc; 1991.

Tarrier N, Barrowclough C, Andrews B, Gregg L. Risk of non-fatal suicide ideation and behaviour in recent onset schizophrenia. Social Psychiatry and Psychiatric Epidemiology. 2004; 39(11):927937. [PubMed: 15549247] 
Van Damme L, Colins OF, Vanderplasschen W. Gender differences in psychiatric disorders and clusters of self-esteem among detained adolescents. Psychiatry Res. 2014; 220(3):991-997. [PubMed: 25454118]

Vater A, Schroder-Abe M, Schutz A, Lammers CH, Roepke S. Discrepancies between explicit and implicit self-esteem are linked to symptom severity in borderline personality disorder. J Behav Ther Exp Psychiatry. 2010; 41(4):357-364. [PubMed: 20435296]

Vracotas N, Iyer SN, Joober R, Malla A. The role of self-esteem for outcome in first-episode psychosis. Int J Soc Psychiatry. 2012; 58(1):41-46. [PubMed: 20826497]

Warman DM, Lysaker PH, Luedtke B, Martin JM. Self-esteem and delusion proneness. J Nerv Ment Dis. 2010; 198(6):455-457. [PubMed: 20531127] 


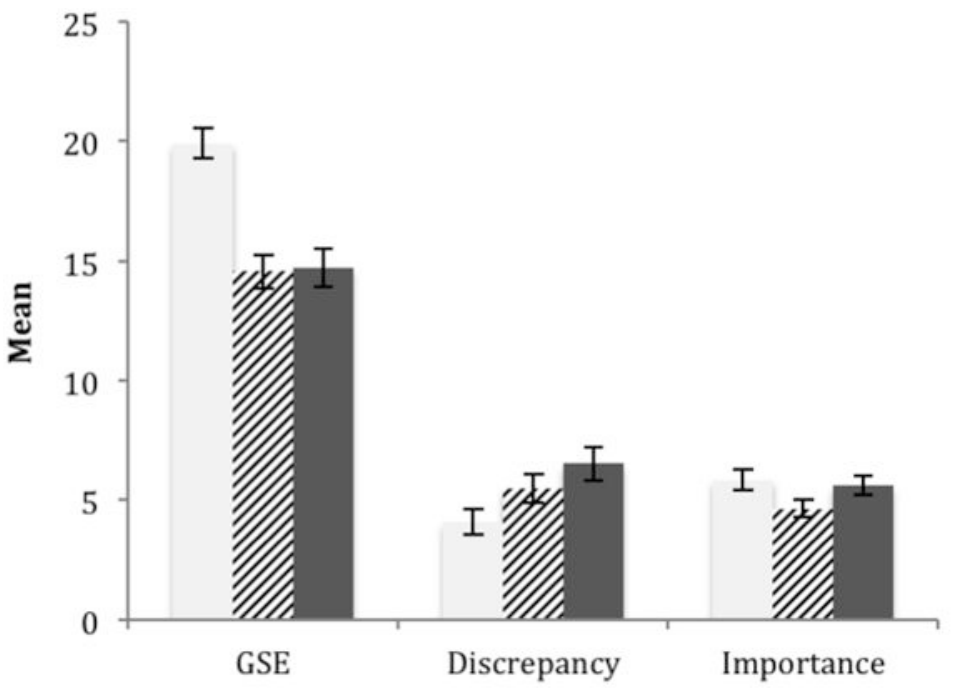

Healthy controls

" High risk

- Schizophrenia

Figure 1. Comparisons of Self-Esteem, Discrepancy, and Importance Scores among Healthy Controls, Individuals at Clinical High Risk for Psychosis, and Individuals with Schizophrenia 


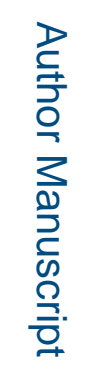

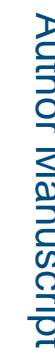

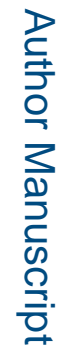

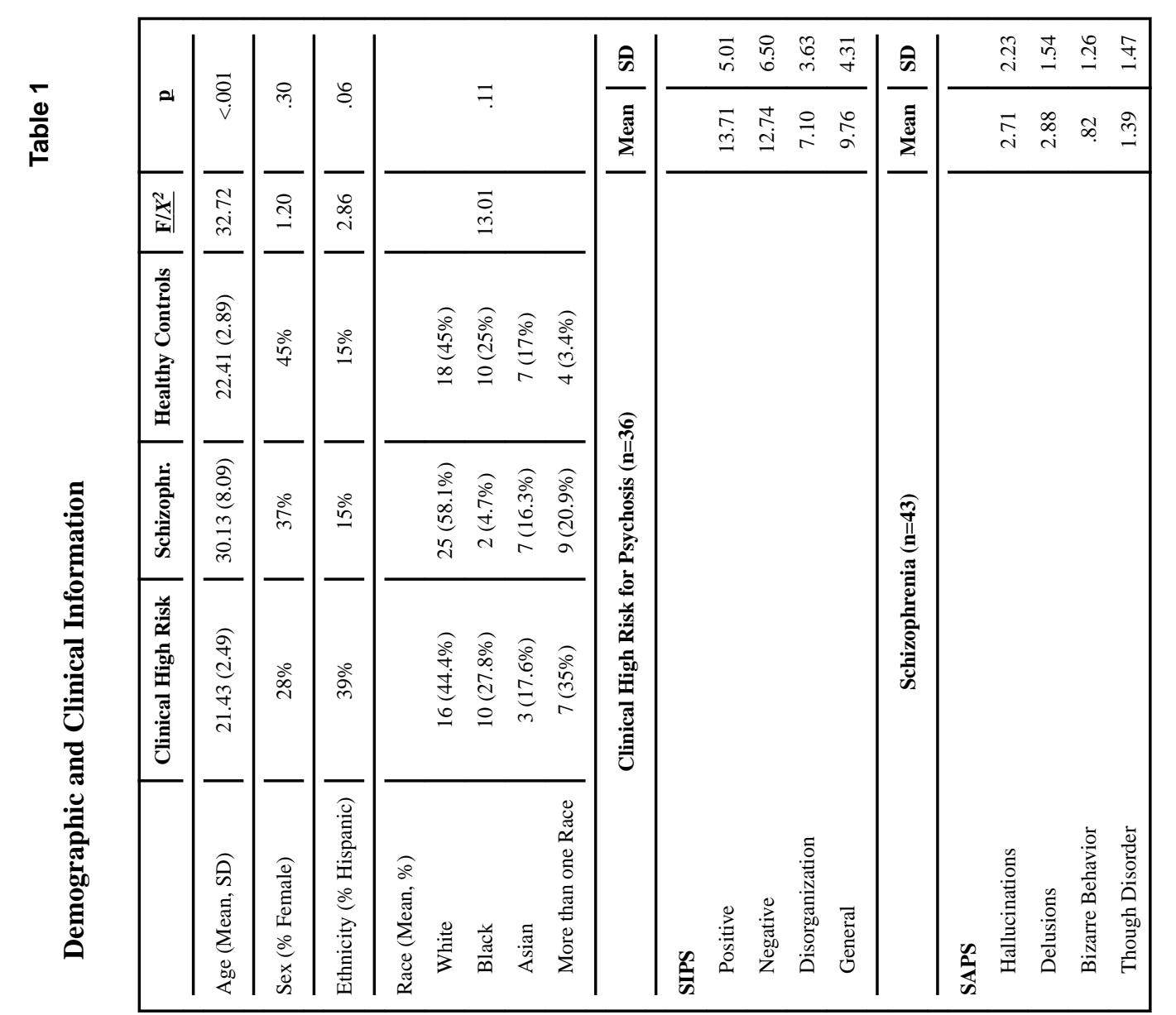

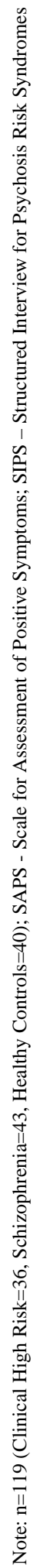

J Nerv Ment Dis. Author manuscript; available in PMC 2019 June 01. 


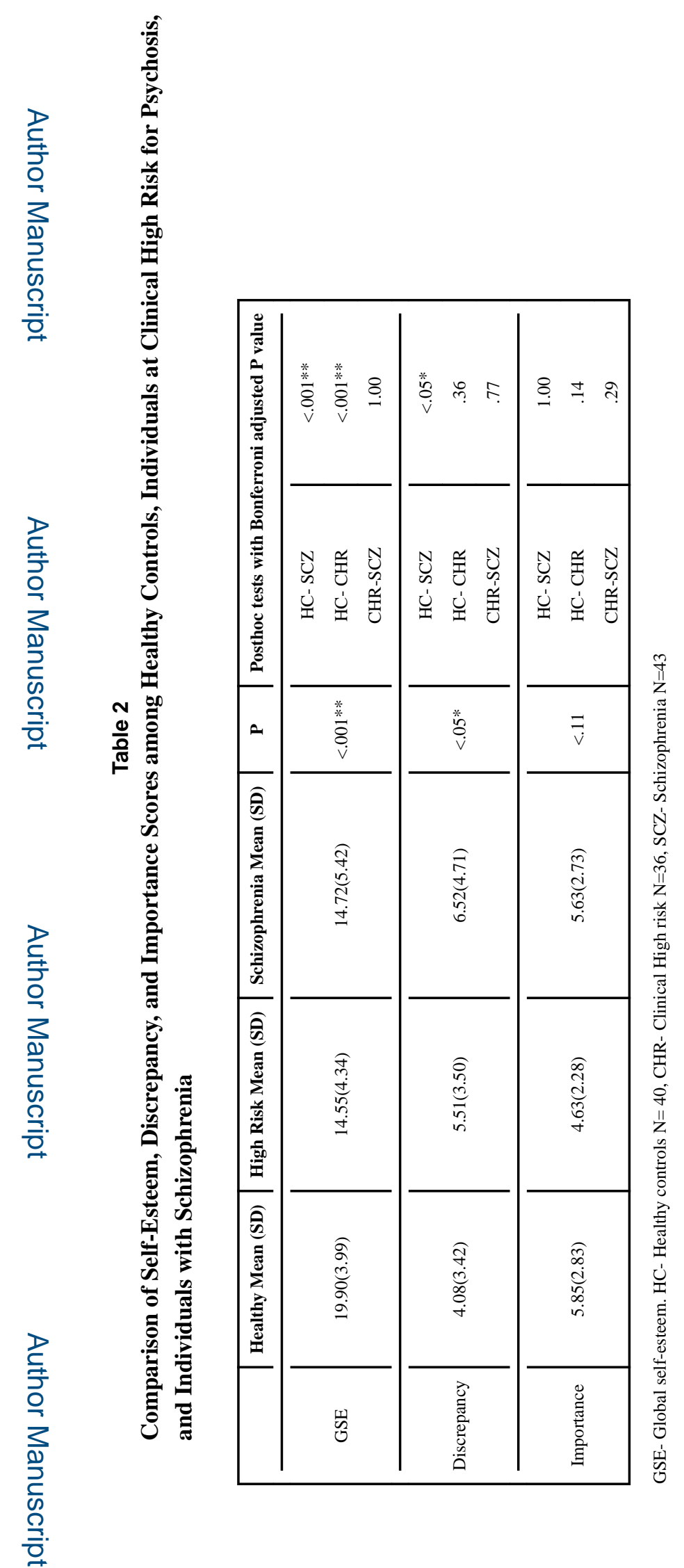

J Nerv Ment Dis. Author manuscript; available in PMC 2019 June 01. 
Table 3

Associations of Self-Esteem, Discrepancy, and Importance Scores with Symptom Domains among Individuals at Clinical High Risk for Psychosis

\begin{tabular}{|c|c|c|c|}
\hline SIPS Symptom Domain & Self-Esteem & Importance & Discrepancy \\
\hline Positive & -0.08 & -0.04 & -0.09 \\
\hline Negative & $-0.41^{* *}$ & $-0.58^{* *}$ & -0.16 \\
\hline Disorganization & $-0.39^{*}$ & $-0.42^{*}$ & -0.17 \\
\hline General & $-0.42^{* *}$ & -0.11 & 0.04 \\
\hline
\end{tabular}

$$
\begin{aligned}
& \mathrm{N}=36 ; \\
& *<0.05, \\
& * * 00.01 ;
\end{aligned}
$$

Associations calculated using Pearson product-moment correlations; SIPS - Structured Interview for Prodromal Symptoms. Self-esteem - average of items assessing global self-esteem; Importance - number of domains deemed "Very Important" (rating=4); Discrepancy - importance ratings minus the competence scores in domains with rating of 4 ("Very Important"). 